\title{
FORM OF ENTRY
}

The format used in the descriptions follows that employed by N. R. Ker in Medieval Manuscripts in British Libraries, 3 vols. (Oxford 1969-1983).

1. Heading. Each entry begins with library and call number, figure number (if any) in this catalog, author and brief title, and place and date. The place and date, when not specified in the manuscript, have been determined by style of script and decoration and, when applicable, by external evidence. Place names refer to geographical regions, rather than to modern political entities. The sigla used for the dates of the manuscripts are on this model: s. XIII in (saeculo XIII ineunte) for the beginning of the thirteenth century; s. $\mathrm{XIII}^{1}$ for the first half of the century; s. XIII ${ }^{\text {med }}$ (saeculo XIII medio) for the middle of the century; s. XIII ${ }^{2}$ for the second half of the century; s. XIII ${ }^{\text {ex }}$ (saeculo XIII exeunte) for the end of the century; s. XIII-XIV for the turn of the thirteenth to the fourteenth century.

2. Contents. In the case of composite volumes (volumes of two or more originally separate books subsequently bound together), the original books are described first in their contents, then in their physical aspect under roman numerals I and II (etc.). Within the contents section of all manuscripts, the text is broken into arabic-numbered sections for ease of reference; the numbered sections, which were fixed by the compilers of this cata$\log$, do not always correspond to obvious divisions in the manuscripts (e.g., in long series of prayers in devotional books). A folio is referred to by a numeral alone if a recto is intended, and by a numeral with a lower case " $v$ " for a verso; the form " $f$. $1 r-v$ " means that both recto and verso of that leaf are considered; " $a$ " and " $b$ " refer to the first and the second column on a given page. In transcription, all abbreviations have been expanded silently. Square brackets signal an offered but uncertain transcription, enclosing either the doubtful words, word, or part of word, or a question mark which refers to the immediately preceding word. Angle brackets occur where no solution for the difficulty is attempted; they may enclose a question mark or a reason for the complete illegibility, such as

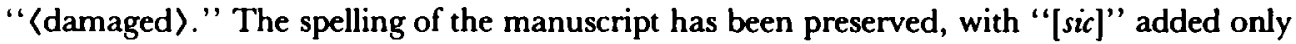
when the form of the word seemed unlikely or such as to cause the reader to suspect a typographical error. We have retained the manuscripts' ę/e/æx, as they show relative distance from classical Latin; $i / j$, however, have been uniformly rendered as $i$; $u / v$ have been distinguished according to modern use for ease of reading. Proper nouns are capitalized. Rubrics, whether in red ink, underlined, in a display script, or merely distinguished from the main body of the text by a space, are here rendered in italics. In the case of the series of brief texts or excerpts in patristic miscellanies, we have given only the rubric (omitting incipit and explicit of the text); in the case of series of prayers, we have preferred, as an 
aid to identification, to give a slightly longer incipit and no explicit, since the prayers tend to end with long, and frequently interchangeable, formulas. In liturgical books, saints' names are generally given in the form used by F. G. Holweck, A Biographical Dictionary of the Saints (St. Louis 1924), a convenient standard. A double diagonal slash // means that a text begins or ends defectively; ellipses signal omitted text. Following each numbered section of the text, where applicable, is a brief bibliographical notice of editions, of lists of manuscripts, of identifying number in the appropriate repertory (e.g., Schneyer, Stegmüller, Walther).

3. Physical description. This is arranged in roughly the order in which the book was produced. The term "parchment" is used throughout for all animal skins, since the traditional distinction between parchment and vellum seems to have been based more on quality of preparation than on knowledge of biological differences between sheepskin and calfskin. For manuscripts on paper, we have attempted to identify watermarks according to their similarity, or least dissimilarity, to the tracings in Briquet. The number of leaves is in roman numerals for endleaves, arabic for those of the book itself. Measurements are in millimeters: first, height and width of the book; then, in parentheses, height and width of the ruled space. The numbers are, of course, approximations, since within any book there is considerable variation; we have preferred to measure ruled rather than written space, because it seemed to offer more consistency. The collation uses arabic numerals for the gatherings, with the number of leaves in that gathering in a suprascript arabic numeral; irregularities are given in parentheses, with the number showing the position in the quire of the irregular leaf; thus $1^{8}(-6)$ means a quire of eight leaves of which the sixth is missing; $1^{8}(+9)$ means that the quire of eight leaves has a leaf added in the ninth position, i.e. at the end. Ruling is specified as to device used or color (hard or dry point; lead, i.e. in a scratching gray or black; crayon, i.e. in a scratchy brown; ink; pale red ink); ownerproduced manuscripts were often frame ruled, with no horizontal lines to guide the copyist. An effort has been made to distinguish the number of copyists and the leaves copied by each. Scripts are identified by a relatively restricted and simple nomenclature. As regards decoration, the height of initials is given in number of vertical lines of text space occupied; colors are mentioned summarily since their names are too subjective to be of value. The subjects of the miniatures have been given in brief terms and, in the case of liturgical books and particularly books of hours, tied to the text to which they belong, since the two function as a cohesive unit. The binding statement is somewhat more expansive for medieval or renaissance bindings than for early modern or modern bindings.

4. Provenance. This section deals with the origin and subsequent ownership of the manuscript. In it we have summarized the evidence regarding date and place of origin given in the contents and physical description sections.

5. A secundo folio reference (the opening words of the second leaf) is supplied for manuscripts that may have belonged to an institution in the Middle Ages and thus have been listed in a medieval inventory.

6. Bibliography. The bibliography cited here refers to the manuscript as a whole, rather than to its parts. 